\title{
NUMERICAL ALGORITHM FOR BEAM RESIDUAL STRESS IDENTIFICATION
}

\begin{abstract}
The goal of the paper is the numerical study of the original hysteresis computational material models and their application in beam's bending theory. The paper presents the chosen differential material models and approaches based on step by step solution respecting the elastic and plastic conditions. In the centre of authors' interest is the numerical method study of the plastic zones identification or study of residual stresses distribution in the beam's cross-section. The results obtained from new MATLAB's programs are compared with FEM models in ADINA.
\end{abstract}

Keywords: Stress identification and distribution, plastic zones, elastic-plastic analysis, MATLAB, ADINA, FEM analysis.

\section{Introduction}

Numerical simulation of the construction materials elasticplastic behaviour is an important part of the various scientific works and studies today. A non-linear behaviour of the material does not mean the complete loss of bearing; it leads to the modification of some mechanical properties and to the stress redistribution in the structure caused by the plastic zones formation. In the case of simulation of the object behaviour under the loading exceeding the yield stress there are several problem types [1, 2, 3, 4, 5 and 6]:

- definition of the applicable elastic-plastic mathematical model,

- knowledge about material "constants" used in the model,

- choice of applicable computing tool or method (FEM, etc.),

- possibility to verify the computed values with the experiment,

- other specific problems (temperature influence, etc.).

The paper target will be to present the chosen mathematical models for the numerical solving of the beam elastic-plastic behaviour with the consequent plasticized zones identification in the cross-section area and residual stresses distribution. Continuous and discontinuous model analysis will be performed on a numerical example and compared with the FEM model in ADINA. The main goal of the structure state elastic-plastic analysis is to determine the stress, strain and boundaries between the elastic and plastic zone. This is true for the structure exposed to outer forces during the whole loading distribution [7]. There are two main theories of the elastic-plastic analysis; plastic flow theory and plastic strain theory.
Plastic flow theory assumes that the stress and strain state depends on the load history. This leads to the incremental problem solving, i.e. step by step. Loading will gradually grow with the step of $\Delta F$ and for each load increment it is needed to evaluate the strain and stress state in particular areas. The method then evaluates if these areas have been plasticized. This theory simulates the real behaviour in a better way but it is more time consuming [8 and 9].

Plastic strain theory is based on the idea that the loading itself does not depend on the trajectory and, therefore, it is not necessary to track the stress history. The problem can be solved by loading the structure by whole force $F$ without any increments. The results are obtained by the analysis of the given nonlinear differential system. The theory is currently used very rarely; it is applicable just for the small range of materials, slow and monotonic loading and for simple problems with very small deformation speed [5].

\section{Algorithms proposition}

\subsection{Proposed model No. 1}

A new numerical approach will be presented; this approach allows analyzing the stress level throughout the whole crosssection area in the case of its plasticization [10 and 11]. The process is based on stress vector increment calculation $\Delta \sigma(t)$ which defines discrete distribution of the stress increment in the

\footnotetext{
* Milan Saga, Milan Vasko, Peter Kopas, Lenka Jakubovicova

Department of Applied Mechanics, Faculty of Mechanical Engineering, University of Zilina, Slovakia

E-mail: milan.saga@fstroj.uniza.sk
} 
cross-section area. This increment will be added to the existing stress in the beam [5].

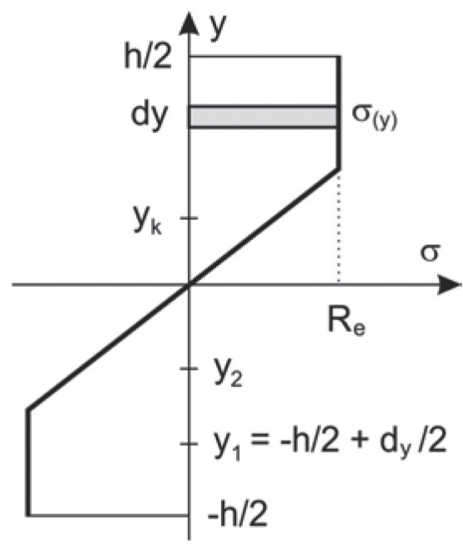

Fig. 1 Correction of the vector $\sigma_{L}^{i+1}(t)$

The basic iterative equation for the calculation is

$\sigma_{L}^{i+1}(t)=\sigma^{i}(t)+\Delta \sigma_{L}^{i}(t)$

where $i$ represents the iteration step, $\sigma_{L}^{i+1}(t)$ is vector describing the quasi-linear stress distribution on which the correction must be applied, $\sigma_{L}^{i}(t)$ is the stress in the cross-section, $\Delta \sigma_{L}^{i}(t)$ is vector of the stress increments depending on loading values (internal values in the beam - bending moment $M o$, axial force $N)$. The next step is the correction of the vector $\sigma_{L}^{i+1}(t)$ in accordance with Fig. 1, i.e.

$\sigma_{k}^{i+1}(t)=\sigma_{L k}^{i+1}(t)$ if $\left|\sigma_{L k}^{i+1}(t)\right|<R_{e}$,

$\sigma_{k}^{i+1}(t)=R_{e} \cdot \operatorname{sgn}\left(\sigma_{L k}^{i+1}(t)\right)$ if $\left|\sigma_{L k}^{i+1}(t)\right|<R_{e}$.

The vector of the stress increments depending on loading values is described by

$\Delta \sigma_{L}^{i}(t)=\Delta \sigma_{L N}^{i}(t)+\Delta \sigma_{L M}^{i}(t)$,

where $\Delta \sigma_{L M}^{i}(t)$ is the vector of the stress increments depending on bending moment and $\Delta \sigma_{L N}^{i}(t)$ is vector of the stress increments depending on the axial force. These increments can be obtained like

$\Delta \sigma_{L N}^{i}(t)=\frac{1}{S} \cdot \Delta \mathrm{F}^{i}(t)$,

$\Delta \sigma_{L M}^{i}(t)=\frac{\Delta M o_{z}^{i}(t)}{J_{z}} \cdot \mathbf{y}$,

where $J_{z}$ is quadratic cross-section moment to the axis of $z, S$ is cross-section area of the beam, $\Delta \mathrm{F}^{i}(t)$ is vector of the difference between the loading force and the force calculated from the stress distribution in the beam cross-section. $\mathrm{y}=\left[y_{1}, y_{2}, \ldots, y_{k}, \ldots, y_{n}\right]^{\mathrm{T}}$ is the discrete vector of the beam's height coordinates $\langle(-h+d y) / 2 ;(h-d y) / 2\rangle$ and $\Delta M o_{z}$ is the difference between the loading moment and the moment calculated from the stress distribution in the beam cross-section (with constant width $b$ )

$\Delta M o_{z p}^{i}(t)=M o_{z d}(t)-M o_{z p}^{i}(t)$.

The $M o_{z d}(t)$ is the loading bending moment to the axis of $z$ and $M_{z p}^{i}(t)$ is the moment really transferred by the beam, calculated as

$M o_{z}^{i}(t)=\int_{S} \sigma^{i}(t) \cdot y \cdot d S=\sum_{i=1}^{n}\left[\sigma_{j}^{i}(t) \cdot y_{j}\right] \cdot d y \cdot b$

After the substitution of equations (6) and (7) into eq. (5), the result equation will be

$\Delta \sigma_{L M}^{i}(t)=\left\{M o_{z d}(t)-\sum_{i=1}^{n}\left[\sigma_{j}^{i}(t) \cdot y_{j}\right] \cdot d y \cdot b\right\} \cdot \frac{1}{J_{z}} \cdot \mathrm{y}$.

The $\Delta \mathrm{F}^{i}(t)$ is vector of variation between the loading force and the axial force calculated from the stress distribution

$\Delta \mathrm{F}^{i}(t)=\left[F_{z}(t)-F_{p}^{i}(t)\right] \cdot \mathrm{E}_{(n \times 1)}$,

where $F_{z}(t)$ is the loading force, $\mathrm{E}_{(n \times 1)}$ is unit vector and $F_{p}^{i}(t)$ is the axial force calculated from the stress distribution

$F_{p}^{i}(t)=\int_{S} \sigma^{i}(y, t) \cdot d S=\sum_{j=1}^{n}\left[\sigma_{j}^{i}(t)\right] \cdot d y \cdot b$.

After the substitution of equations (9) and (10) into eq. (4), it can be obtained

$\Delta \sigma_{L N}^{i}=\left\{F_{z}(t)-\sum_{j=1}^{n}\left[\sigma_{j}^{i}(t)\right] \cdot d y \cdot b\right\} \cdot \frac{1}{S} \cdot \mathrm{E}_{n x 1}$,

and after the substitution of equations (8) and (11) into eq. (3) is $\Delta \sigma_{L}^{i}(t)=\left\{F_{z}(t)-\sum_{j=1}^{n}\left[\sigma_{j}^{i}(t)\right] \cdot d y \cdot b\right\} \cdot \frac{1}{S} \cdot \mathrm{E}_{n \times 1}+$ $\left\{M o_{z d}(t)-\sum_{i=1}^{n}\left[\sigma_{j}^{i}(t) \cdot y_{j}\right] \cdot d y \cdot b\right\} \cdot \frac{1}{J_{z}} \cdot \mathrm{y}$.

After the substitution of equation (3) into (1)

$$
\begin{aligned}
& \Delta \sigma_{L}^{i+1}(t)=\left\{F_{z}(t)-\sum_{j=1}^{n}\left[\sigma_{j}^{i}(t)\right] \cdot d y \cdot b\right\} \cdot \frac{1}{S} \cdot \mathrm{E}_{n x 1}+ \\
& \left\{M o_{z d}(t)-\sum_{i=1}^{n}\left[\sigma_{j}^{i}(t) \cdot y_{j}\right] \cdot d y \cdot b\right\} \cdot \frac{1}{J_{z}} \cdot \mathrm{y}+\sigma_{\mathrm{L}}^{\mathrm{i}}(\mathrm{t}) .
\end{aligned}
$$

The time stress distribution is obtained by discrete step by step solution. Starting step appears from non-loaded state, in each next step loading grows and eq. (1) is solved as long as $\left\|\sigma^{i+1}-\sigma^{i}\right\| \leq \varepsilon$, if $\varepsilon \rightarrow 0$. 


\subsection{Proposed model No. 2}

The stress distribution in the beam made from an ideal elasticplastic material can be expressed using the continuous equation

$$
\begin{aligned}
& \Delta \sigma(M o)=\left(1-\left|\frac{\sigma}{R_{e}}\right|^{n}\right) \cdot \Delta y \cdot\left[\frac{2 \cdot \sigma_{L}}{h}-\left(\frac{2 \cdot \sigma_{L}}{h}-\right.\right. \\
& \left.\left.\frac{2 \cdot R_{e}}{h \cdot \sqrt{2 \frac{R_{e}-\sigma_{L}}{R_{e}}+1}}\right) \cdot \frac{\operatorname{sgn}\left(\sigma_{L}-R_{e}\right)+1}{2}\right]
\end{aligned}
$$

where $R_{e}$ is yield stress, $\sigma_{L}$ is linear stress, $M_{O}$ is the bending moment and $W_{o}$ is the bending cross-section modulus. Equation (14) describes the stress distribution in the beam's cross-section depending on bending moment

$M o^{i+1}(t)=M o^{i}(t)+\Delta M o^{i}(t)$,

where $i$ is iteration step and $\Delta M o$ is increment of the bending moment. The stress distribution in time is calculated by iteration equation

$\sigma^{i+1}(t)=\sigma^{i}(t)+\Delta \sigma^{i}(t)$

where $\sigma$ is the stress vector in cross-section and $\Delta \sigma$ is vector of the stress increments in the cross-section area,

$$
\begin{aligned}
& \Delta \sigma^{i}(t)=\Delta \sigma_{z}^{i}(t)-\left[\Delta \sigma_{z}^{i}(t)-\Delta \sigma_{o}^{i}\right] . \\
& \frac{\operatorname{sgn}\left[-M o^{i}(t) \cdot \Delta M o^{i}(t)\right]+1}{2}
\end{aligned}
$$

where $\Delta \sigma_{z}^{i}(t)$ is vector of the stress increments in the crosssection (under load) and $\Delta \sigma_{o}^{i}(t)$ is vector of the stress increments in the cross-section (unloading). The $\Delta \sigma_{z}^{i}(t)$ can be calculated like

$$
\Delta \sigma_{z}^{i}(t)=\sigma\left[M o^{i}(t)+\Delta M o^{i}(t)\right]-\sigma\left[M o^{i}(t)\right],
$$

where $\sigma\left[M o^{i}(t)+\Delta M o^{i}(t)\right]$ is the stress vector obtained from equation (7) at the moment $M o^{i}(t)+\Delta M o^{i}(t)$ and $\sigma\left[M o^{i}(t)\right]$ is the stress vector obtained from equation (7) at the moment $M o^{i}(t)$. And

$\Delta \sigma_{o}^{i}(t)=\frac{\Delta M o^{i}(t)}{J_{z}} \cdot \mathrm{y}$,

where $\Delta M o^{i}(t)$ is the moment increment. After the substitution, the vector of the stress in the cross-section in the $i+1$ step will be

$$
\begin{aligned}
& \sigma^{i+1}=\sigma^{i}+\Delta \sigma_{z}^{i}(t)-\left[\Delta \sigma_{z}^{i}(t)-\Delta \sigma_{o}^{i}(t)\right] . \\
& \frac{\operatorname{sgn}\left[-M o^{i}(t) \cdot \Delta M o^{i}(t)\right]+1}{2}
\end{aligned}
$$

\subsection{D generalization}

In the case of 3D geometrical problem, the calculation starts from the equation (1) and the next step is a correction of the vector $\sigma_{L}^{i+1}(t)$ by

$\sigma^{i+1}(t)=\sigma_{L}^{i+1}(t)$ if $\left|\sigma_{L k}^{i+1}(t)\right|<R_{e}$,

$\sigma^{i+1}(t)=\sigma_{L}^{i+1}(t)-\Delta \sigma_{L}^{i}(t) \cdot(1-\alpha)$ if

$\left|\sigma_{L k}^{i+1}(t)\right|>R_{e}$.

The vector of the stress increments depending on the loading parameters is described like

$\Delta \sigma_{L}^{i}(t)=\Delta \sigma_{L N}^{i}(t)+\Delta \sigma_{L M y}^{i}(t)+\Delta \sigma_{L M z}^{i}(t)$,

where $\Delta \sigma_{L M y}^{i}(t)$ and $\Delta \sigma_{L M z}^{i}(t)$ are vectors of the stress increments from bending moments in $y$ and $z$ axes. The $\Delta \sigma_{L N}^{i}(t)$ is vector of the stress increments depending on axial force, these increments can be obtained by equations

$\Delta \sigma_{L N}^{i}(t)=\frac{1}{S} \cdot \Delta \mathrm{F}^{i}(t)$,

$\Delta \sigma_{L M z}^{i}(t)=\frac{\Delta M o_{z}^{i}(t)}{J_{z}} \cdot \mathrm{y}$,

$\Delta \sigma_{L M y}^{i}(t)=\frac{\Delta M o_{y}^{i}(t)}{J_{y}} \cdot \mathrm{z}$,

where $J_{z}$ and $J_{y}$ are quadratic cross-section moments to the axis of $z$ and $y, \mathbf{y}$ and $\mathbf{z}$ are discrete vectors of the beam's height and width coordinates (Fig. 2)

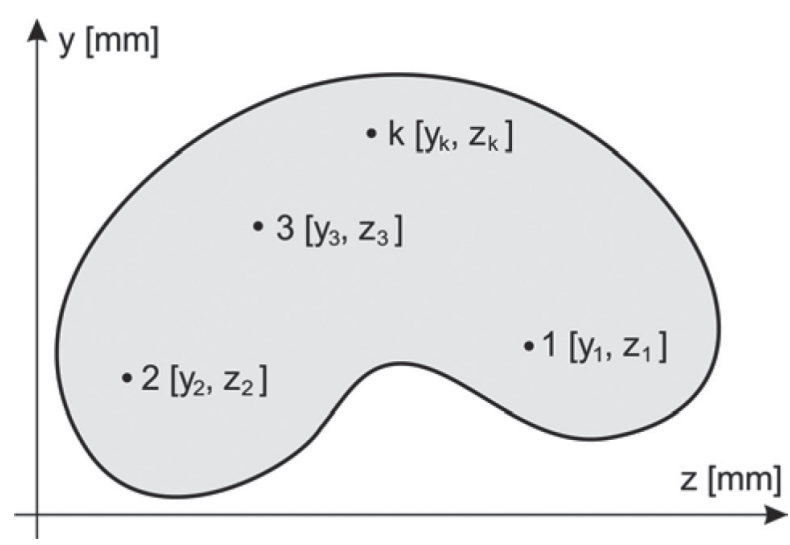

Fig. 2 The vector components

The $\Delta M o_{z}$ and $\Delta M o_{y}$ are differences between the loading moment and the moment calculated from the stress distribution in the beam cross-section,

$\Delta M o_{z}^{i}(t)=M o_{z d}(t)-M o_{z p}^{i}(t)$, 
where $M o_{z d}(t)$ is the loading bending moment to the axis of $z$ and $M o_{z p}^{i}(t)$ is moment really transferred by the beam, calculated as

$M o_{z p}^{i}(t)=\int_{S} \sigma^{i}(t) \cdot y d S=\sum_{i=1}^{n}\left[\sigma_{j}^{i}(t) y_{j}\right] \cdot d y d z$.

The result equation for calculating $\Delta \sigma_{L M z}(t)$ will be

$\Delta \sigma_{L M z}^{i}(t)=\left\{M o_{z d}(t)-\sum_{i=1}^{n}\left[\sigma_{j}^{i}(t) \cdot y_{j}\right] \cdot d y d z\right\} \cdot \frac{1}{J_{z}} \cdot \underset{(28)}{\mathrm{y}}$

In a similar way the equation for calculation $\Delta \sigma_{L M y}(t)$ can be derived, i.e.

$\Delta \sigma_{L M y}^{i}(t)=\left\{M o_{y d}(t)-\sum_{i=1}^{n}\left[\sigma_{j}^{i}(t) \cdot z_{j}\right] \cdot d y d z\right\} \cdot \frac{1}{J_{y}} \cdot \mathrm{z}$

and

$\Delta \mathrm{F}^{i}(t)=\left\lfloor F_{2}(t)-F_{p}^{i}(t)\right\rfloor \cdot \mathrm{E}_{(n x 1)}$,

where $F_{z}(t)$ is loading force, $F_{p}^{i}(t)$ is the axial force calculated from stress distribution

$F_{p}^{i}(t)=\int_{S} \sigma^{i}(y, t) \cdot d S=\sum_{j=1}^{n}\left[\sigma_{j}^{i}(t)\right] \cdot d y d z$.

After the substitution of equations (31) and (30) into eq (23), following equation can be obtained

$\Delta \sigma_{L N}^{i}=\left\{F_{z}(t)-\sum_{j=1}^{n}\left[\sigma_{j}^{i}(t)\right] \cdot d y d z\right\} \cdot \frac{1}{S} \cdot \mathrm{E}_{(n x 1)}$.

Time stress distribution is obtained by discrete step by step solution. Starting step appears from non-loaded state, in each next step loading grows and eq. (20) is solved as long as $\left\|\sigma^{i+1}-\sigma^{i}\right\| \leq \varepsilon$, if $\varepsilon \rightarrow 0$.

\section{Numerical study}

A model of beam with bilinear material and proposed computational model No.1 (Fig. 3) was implemented in MATLAB and compared with the more detailed FEM model created and analyzed in ADINA [12 and 13]. The beam was fixed at its one end and loaded at the other end.

The material parameters were: Young's modulus $E=2.1 \cdot 10^{5} \mathrm{MPa}$, yield stress $R_{e}=100 \mathrm{MPa}$ and the hardening coefficient $\alpha=0.1$.

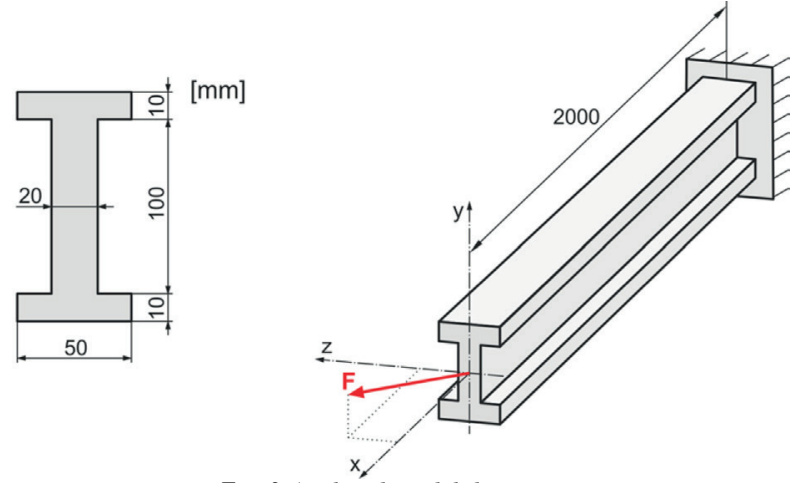

Fig. 3 Analyzed model dimensions

The forces distribution in the $x, y$ and $z$ axes are shown in Figs. 4 and 5.

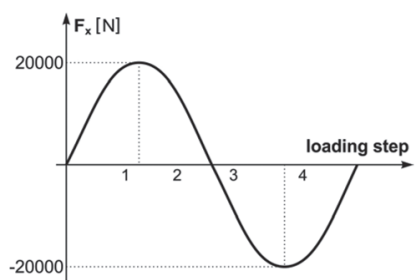

Fig. 4 Axial force behaviour
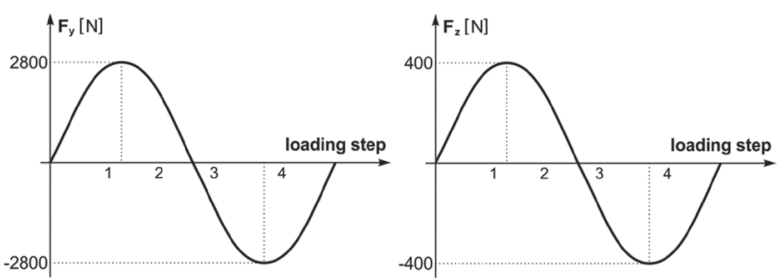

Fig. 5 Forces behaviour in the $y$ and $z$ axes

Comparison of maximum and minimum normal stresses in the particular loading steps is shown in Table 1. The stresses distribution monitored in the particular loading steps is shown in Figs. 6 to 9.

Comparison of maximum and minimum normal stresses

Table 1

\begin{tabular}{|c|c|c|c|}
\hline $\begin{array}{c}\text { Loading } \\
\text { step }\end{array}$ & $\sigma$ & $\begin{array}{c}\sigma[\mathrm{MPa}] \\
\text { (Proposed model No.1 } \\
\text { MATLAB) }\end{array}$ & $\begin{array}{c}\sigma \text { [MPa] } \\
\text { (FEM software } \\
\text { ADINA) }\end{array}$ \\
\hline \multirow{2}{*}{$\mathbf{1}$} & $\sigma_{\max }$ & 113.67 & 107.5 \\
\cline { 2 - 4 } & $\sigma_{\min }$ & -116.4 & -106.0 \\
\hline \multirow{2}{*}{$\mathbf{2}$} & $\sigma_{\max }$ & 23.8 & 20.4 \\
\cline { 2 - 4 } & $\sigma_{\min }$ & -26.3 & -31.6 \\
\hline \multirow{2}{*}{$\mathbf{3}$} & $\sigma_{\max }$ & 122.76 & 121.5 \\
\cline { 2 - 4 } & $\sigma_{\min }$ & -123.52 & -127.1 \\
\hline \multirow{2}{*}{$\mathbf{4}$} & $\sigma_{\max }$ & 16.833 & 23.3 \\
\cline { 2 - 4 } & $\sigma_{\min }$ & -17.18 & -14.7 \\
\hline
\end{tabular}




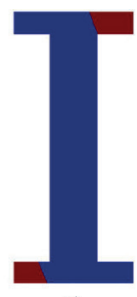

Plastic zones (MATLAB)

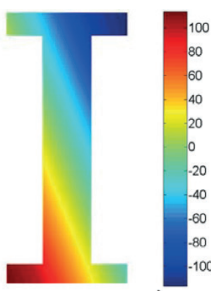

b)

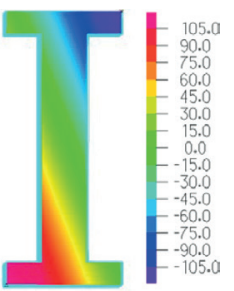
Normal stress (ADINA)
Fig. 6 Comparison of normal stress distribution at $1^{\text {st }}$ loading step

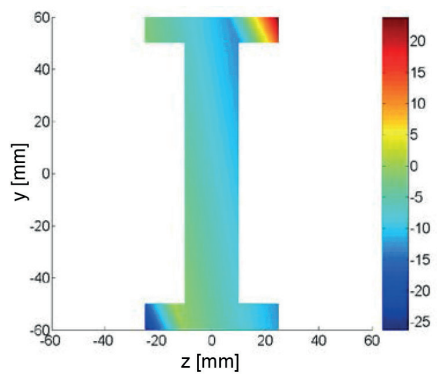

Proposed algorithm in MATLAB

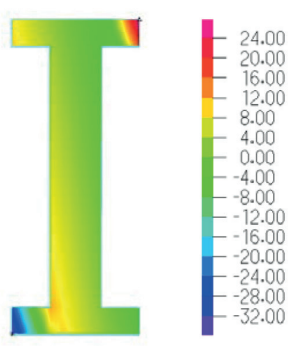

Solution in ADINA
Fig. 7 Comparison of normal stress distribution at the $2^{\text {nd }}$ loading step

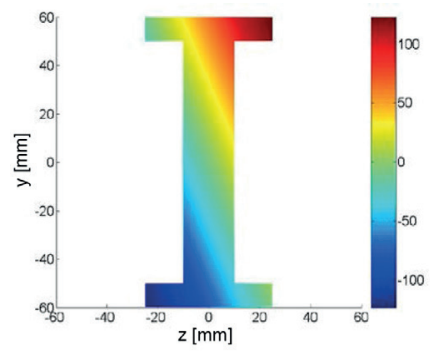

Proposed algorithm in MATLAB

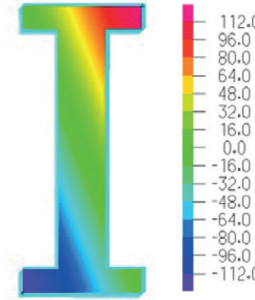

Solution in ADINA
Fig. 8 Normal stress distribution at the $3^{\text {rd }}$ loading step

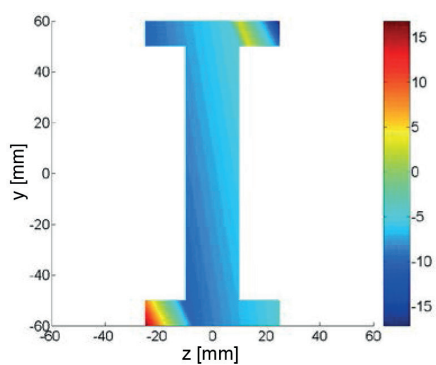

Proposed algorithm in MATLAB

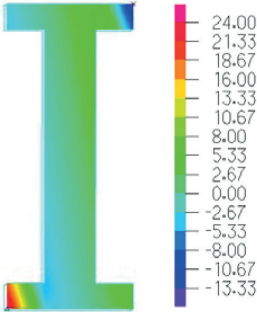

Solution in ADINA

Fig. 9 Normal stress distribution at the $4^{\text {th }}$ loading step

\section{Conclusion}

The paper goal has been to present the study of new numerical approaches for plastic zones identification and residual stresses distribution in the cross-section area of the beams stressed above yield strength. The reason why this study was realized is to determine the stresses during the solution of the elastic-plastic structures state modelled by the beam finite elements.

According the authors' opinion, the graphical presentation of the residual stress distribution in the beam cross-section after application of the higher number of cycles can be important information from the view of the bearing capacity and reliability of the analyzed objects.

\section{Acknowledgement}

This work has been supported by VEGA grant 1/0234/13.

This contribution is the result of the project implementation: Development of optimum technology for the analysis of limit states of structural elements in contact, ITMS code 26220220118, supported by the Research \& Development Operational Programme funded by the ERDF.
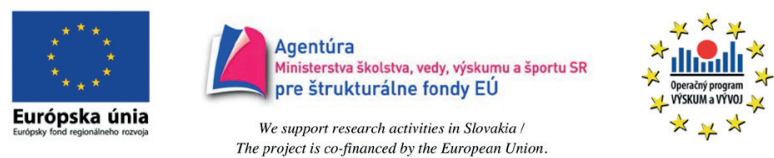

\section{References}

[1] CZAN, A., TILlOVA, E., SEMCER, J., PILC, J.: Surface and Subsurface Residual Stresses after Machining and their Analysis by x-ray Diffraction. Communications - Scientific Letters of University of Zilina, vol. 15, No. 2, 2013, 69-76, ISSN 1335-4205.

[2] EDWARDS, S. K., MCKEE, R. B., Jr.: Fundamentals of Mechanical Component Design. USA, 1991.

[3] KOMPIS, V., NOVAK, P., HANDRIK, M.: Finite Displacements in Reciprocity-based FE Formulation. Computer Assisted Mechanics and Engineering Sciences, vol. 9, No. 4, 2002, 469-480, ISSN 1232-308X.

[4] KUCERA, L., GAJDOSIK, T.: The Vibrodiagnostic of Gears. Proc. of $54^{\text {th }}$ Intern. conference of machine design departments, September, 2013, Hejnice - Liberec : Technical university, 93-98, ISBN 978-80-7372-986-8.

[5] SAGA, M., VASKO, M.: Stress Sensitivity Analysis of the Beam and Shell Finite Elements. Communications - Scientific Letters of the University of Zilina, vol. 11, No. 2, 2009, 5-12, ISSN 1335-4205. 


\section{COMMNICOIIIONS}

[6] STANCEKOVA, D., SEMCER, J., DERBAS, M., KURNAVA, T.: Methods of Measuring of Residual Stresses and Evaluation of Residual State of Functional Surfaces by x-ray Diffractometric Methods. Manufacturing Technology, vol. 13, No. 4, 2013, 547-552, ISSN 1213-2489.

[7] VAVRO, J.: Optimization of the Design of Cross-sectional Quantities in Transport Machines and Equipment. Studia i materialy, Zelena Hora, 1998, 186-194.

[8] KRAJNAK, J., GREGA, R.: Comparison of Three Different Gases and their Influence on Dynamic Properties One-bellow and Two-bellows Flexible Pneumatic Coupling. Zeszyty naukowe Politechniki Slaskiej: Transport, No. 81, 2013, 79-84, ISSN 0209-3324.

[9] LACK, T., GERLICI, J.: Modified Strip Method Utilization for Wheel/rail Contact Stress Evaluation. ${ }^{\text {th }}$ Intern. Conference on Contact Mechanics and Wear of Rail/wheel Systems (CM 2012), August 2012, Chengdu: Southwest Jiaotong University, 2012, 87-89.

[10] KUCERA, L., LUKAC, M., JURAK, L., BRUMERCIK, F.: Hydromechanical Automatic Transmission. Communications Scientific Letters of the University of Zilina, vol. 11, No. 2, 2009, 33-35, ISSN 1335-4205.

[11] VASKO, A.: Analysis of the Factors Influencing Microstructure and Mechanical Properties of Austempered Ductile Iron. Communications - Scientific Letters of the University of Zilina, vol. 11, No. 4, 2009, 43-47, ISSN 1335-4205.

[12] SAPIETOVA, A., SAPIETA, M., HYBEN, B.: Sensitivity Analysis Application for Multibody System Synthesis. Applied Mechanics and Materials, vol. 420, 2013, 68-73, ISSN 1660-9336.

[13] ZMINDAK, M., NOVAK, P., DEKYS, V., PELAGIC, Z.: Finite Element Thermo-Mechanical Transient Analysis of Concrete Structure. Procedia Engineering, vol. 65, 2013, 224-229, Elsevier, ISSN 1877-7058. 